\title{
Research on Reconstructing the Old Building Space in Inheritance of City Culture-Taking the Architecture of the Taoxichuan in Jingdezhen as an Example
}

\author{
Han Wei \\ School of Art and Design, Ceramic Institute, Jingdezhen 333000, China \\ 809978823@qq.com
}

Keywords: cultural heritage; transformation and upgrading.

\begin{abstract}
There are many state-owned porcelain factories in Jingdezhen, which have made great contributions to the development and promotion of the ceramic culture. However, due to the influence of the market economy, and its own poor management, Jingdezhen porcelain factories gradually closed down to fall into disuse. Under the promotion of the creative culture industry, some old porcelain factories have been transformed to be used, but only limited to the creative industry model of the porcelain culture. Taking Taoxichuan cultural industrial park in Jingdezhen as an example, this paper analyzes the meaning of Jingdezhen post-industrial landscape regeneration and Jingdezhen industrial ruins problems and proposes the strategy of the industrial ruins renovation and landscape regeneration, so as to protect and continue Jingdezhen industrial heritage landscape culture, promote the development of various post-industrial landscape. We start with the transformation and upgrading of Taoxichuan, study and learn from the "Taoxichuan phenomenon", and go to one road to rejuvenate the glorious dream of millennium porcelain capital.
\end{abstract}

\section{The Taoxichuan Phenomenon}

Taoxichuan is located in the old industrial area of Jingdezhen City; there are a large number of ceramic industrial heritages and bears the heavy historical memory of the millennium porcelain culture in Jingdezhen. In the past three years, Jingdezhen municipal government have devoted themselves to promoting the transformation and upgrading of Taoxichuan, protect and utilize its industrial heritage, integrate various elements such as industrial development and upgrade and new urbanization, and make Jingdezhen ceramic culture use the Internet+ to become the most fashionable international models. It has been successfully selected as the model for the the park integration planning demonstration of the Ministry of Housing and Urban-Rural Development. It has become a classic case of 20 national urban designs and has been listed in the 2015 National Cultural Industry Key Project by the Ministry of Culture. It can be said that Taoxichuan is Jingdezhen's best model for the protection and utilization of the ceramic industry heritage.

\section{Transformation and Upgrading of Industrial Heritage is of Great Significance}

Research, protection and reuse of industrial heritage will find new opportunities for urban development. From the point of view of social and economic development, the industrial heritage after protection and development can not only attract more tourists and stimulate local consumption with its unique atmosphere of historical space, but also solve employment problems, increase employment opportunities, and even promote industrial upgrading., improve the competitiveness of the city. From the perspective of historical and cultural protection, industrial heritage bears many memories of urban development. If it is studied, protected and utilized, it will be able to protect the historical and cultural context of the city more effectively. Taking Taoxichuan as an example, it is the most important representative of Jingdezhen's industrial production of modern ceramics. It is an indispensable representative area of Jingdezhen since the Tang Dynasty; it faithfully records the process evolution process and architecture style change, the protection and use of it, not only can 
achieve win-win economic and social benefits, but also can effectively protect the ceramic history and culture of Jingdezhen.

\section{3. "Taoxichuan Phenomenon" Bring Inspiration and Reference}

Taoxichuan has become a phenomenon. Its unique ceramic gene, multi-culture, mixed-use modes, and conservation and utilization patterns have become samples of the transformation and upgrading of traditional ceramics industries, Examples of the protection of modern ceramic industry heritage, which are being simulated by many domestic cities. Studying this phenomenon can not only provide reference for the subsequent development of Taoxichua and the upgrading and transformation of other industrial districts in Jingdezhen, but also Jingdezhen keep pace with the construction pace of country, plays an important role in promoting "rejuvenate the ancient town with 1000 years, recreate the porcelain capital of the world, protect ecological homes, and build a famous tourist city, create a city that communicate with the world", there are mainly five aspects.

The first is to seize the main line and ensure a complete historical context. To upgrade and transform the industrial heritage, it is necessary to enable it to achieve economic development while retaining its historical features and cultural values. Taoxichuan as the most important representative of Jingdezhen's modern ceramics industrialization, which has not only original ceramic raw materials, smelting, painting and related tools and objects in the area, but also various ceramic workshops, galleries and studios. Porcelain artists created on the scene, and there are imagery demonstrations of porcelain intangible cultural heritage inheritors tell about the modern ceramic processes, work scenes, and ceramic historians moving stories, form a clear Jingdezhen porcelain industry history and culture development context. Therefore, when other industrial areas are undergoing transformation and upgrading, they should also comprehensively apply arts, ecology, culture, and other treatment methods to re-protect and use the original desolate and deserted industrial land, excavate the cultural connotations, and revitalize new areas, and it has become a soul place for the continuation of Jingdezhen's culture.

The second is to highlight features, classify and transform city. When transforming the industrial heritage districts of Jingdezhen, it is necessary to act according to circumstances, design different schemes according to different types, and preserve the culture and history it carries in a live manner, instead of only rigidly maintaining those historic buildings. For example, architecture expo mainly aims at those industrial architectural heritages with important historical, scientific and cultural values, protects original site and highlights its historical authenticity, thereby evoking citizens' historical memories and cultural identity. The landscape park type mainly aims at industrial heritages with open spaces and abandoned building. On the basis of preserving its original features, various landscape elements are integrated, animation elements, and antique elements form distinctive urban landscape spaces. Cultural and creative type mainly aims at industrial heritage buildings and areas with unique visual characteristics, adopt old-fashioned methods, and introduce catering, leisure, entertainment and other industries to make it to be a culturally creative industry gathering area with. As a result, the characteristics of different industrial heritage areas are highlighted and their advantages are maximized.

The third is industrial support, establish and improve the industrial chain. The development of any region cannot be separated from the support of the industry. For Jingdezhen, promoting the transformation and upgrading of the ceramic industry heritage is to seize the opportunity for construction and build a complete industrial chain including design, production, promotion, and trading and so on. For example, with the promotion of cultural activities, various large-scale art exhibitions, art festivals public welfare cultural lectures and academic report meetings are held to enhance the cultural quality of Jingdezhen. Through the salvage of historical documents, the construction of intangible protection platforms, precious objects, and photo materials and make the ceramic culture in Jingdezhen resplendent. The tools, craftsmanship, history of working population, and identity documents of porcelain workers in Jingdezhen have been displayed in a concentrated 
manner. The ceramic culture of Jingdezhen was revived. The innovative ideas as the starting point, we will set up a creative design platform and cooperate with high-end museums, exhibition halls and shopping malls at home and abroad. The plan is based on the full coverage of food, clothing, housing and transportation, and builds a leisure and entertainment platform to attract people to stay, eat, academic seminars, business meetings, and fitness and entertainment. This complete industrial chain, not only able to prosper economics and attract people, most importantly, it enables Jingdezhen's industrial heritage areas to form a scale and embarks on a "different" development path that is different from other urban industrial heritage areas.

The fourth is the development of tourism resources to help the global tourism.

Industrial heritage investment value is a close with the changes in the social environment. The general understanding of the social environment actually determines the future trend of purchasing power. Taoxichuan's cultural and creative street due to its international perspectives, ceramic genes, multiculturalism, entrepreneurial innovation, and compound development, it has had a great influence both at home and abroad, attract many celebrities to pay attention to "Taoxichuan" phenomenon. Moreover, from the economic, environmental, social and other comprehensive benefits, Jingdezhen's other industrial heritage areas are also generally related to ceramics, filled with a variety of ceramic cultural elements, transform into urban leisure and industrial tourism is probably their best choice. However, the development of any outstanding tourism resources will become pale and impetuous if it separates from the elements of history and culture. Therefore, Jingdezhen's industrial heritage area has been transformed and upgraded, the hotel, restaurant, bar, shopping center and son are newly built.

At the same time, it is more important to repair old buildings, chimneys, water towers; kilns, etc. tell about the history, culture, art and industrialization of the industrial heritage area with local methods, and to cause public to trace the roots of the culture, it stimulates everyone's interest in history and culture.

The fifth is to grasp the core elements and demonstrate the cultural.

The aim is to allow people of different nationalities and cultures to "communicate" through humanistic exchanges. Humanities exchanges and cooperation have laid a broad social foundation for construction. Jingdezhen's most proud and admired is the millennium ceramics. The industrial heritage in urgent need of transformation and upgrading is also related to the ceramic industry. Most of them are originally porcelain factories. The chimneys, bricks, kilns, equipment, and workshops are just shapes. The culture contained in it is its soul, so when building these industrial heritages, transforming and upgrading them, the most important thing is to highlight the elements of ceramic culture so that they can be distinguished from industrial heritage in other parts of the country, and attracts more eyes and people.

The sixth is to renovate of the interior space of old buildings

The regeneration of post-industrial landscape should not only preserve or update the exterior and environment of the old factory buildings, but also transform and reuse the interior space of industrial buildings. The original building function already does not meet the demand of modern space already, how to integrate new function into old buildings is the primary solution to the renovation of the old building interior space. The inner space of the old building often has the characteristics of large span and large column distance, which makes its space flexible and free; the resistance to repartition space is small. The space plasticity is stronger; moreover, the construction structure is strong, the bearing capacity is strong, and the service life is not long; in addition, the internal structure and pipeline of the building are exposed and have industrial aesthetic value, which provides infinite possibilities for the reuse of the space in the old workshop. Therefore, "Taoxichuan" transformation present diversification trend of architectural space, the space can be commercial, can become the expo site, "Taoxichuan" project turn them into the museum, for artists exhibition also can live for some tall buildings; Low and small span flexible structures can be transformed into an artist studio, other workshop and office building with small construction volume, scattered distribution are reconstructed for catering space or ceramics sales exhibition space. 


\section{Conclusion}

Taoxichuan is not a static cultural heritage, but through economic activities and industrial development, and strengthen the participation of people. After the old factory area was idle, the traditional porcelain economic activity disappeared from physical space. But through cultural creativity, new shape is formed: such as art management. From the ceramic art design creation in industry chain upstream, to the spread and promotion in midstream, to the sales and consumption in downstream, people come back into the physical space, thus generating vibrant cultural space. Historic culture continues to extend, then Taoxichuan truly achieves cultural and social value.

\section{Acknowledgements}

Project source: Research on innovative characteristics of Jingdezhen Chinese Zodiac ceramic culture in Jiangxi Province.

Project source: art planning project of Department of Culture of Jiangxi Province.

Project number: 752005-030

\section{References}

[1]. Hu Yan. Post-industrial landscape design language research [D], Beijing Forestry University, 2014.

[2]. Ma Jianye, Urban leisure environment research and design [M].Beijing: China Machine Press, 2002: 4-19.

[3]. JingZhen, Jingdezhen builds Taoxichuan ceramic culture industrial park [J], Ceramics, 2013 (3): 69-69.

[4]. Dong Cui, Research on the regeneration strategy of industrial landscape of Jingdezhen -- taking "Taoxichuan" ceramic culture industrial park as an example [J], Modern Communication, 2016 (16) :53-54.

[5]. Yuan Yue, Research on the reconstruction mechanism of cultural space of Taoxichuan in Jingdezhen [J], Creation and Design, 2017 (3). 